\title{
Teachers' Perceptions of Distributed Leadership Practice in Three Secondary Schools within Gauteng Province
}

\author{
Kwinda Azwifarwi Aaron \\ University of Johannesburg \\ Pierre du Plessis \\ University of Johannesburg \\ pierredp@uj.ac.za
}

\section{Doi:10.5901/mjss.2014.v5n23p1445}

\begin{abstract}
The post 1994 era brought many changes in South African Education System, including how schools should be governed henceforth. The South African Schools Act, no 96 of 1996 was enacted in the parliament and it challenged the schools to adopt a more inclusive and participative approach in running their affairs. But the school's hierarchical structure remained mandatory and continues to exist even today. It is against this backdrop that this study was conducted to explore the practice of distributed leadership (within school's hierarchical structure) from teacher-based perspective, rather than educational theorists or legislators' point of view. The three sampled secondary schools fall within Johannesburg North District 10 in Gauteng Province. The research design followed a qualitative approach. The data was collected through interviewing the teachers of different post levels (including principals) from the three sampled secondary schools, as individuals and in pairs. To triangulate the data, documents containing minutes of the planning sessions and the first staff meeting were also requested and used to check how duties and responsibilities are allocated to staff members in these three schools. The findings revealed that there are possibilities provided by distributed leadership, and also inherent and inevitable barriers to a distributive approach to leadership in the three secondary schools. The possibilities are that distributing leadership can raise school's collective capacities, empower staff, and can encourage collaborative school cultures and decision-making; and as a result schools can function effectively because of the presence of collective agency in the execution of tasks. However, the barriers posed by the school's hierarchical structure and the policy climate within which schools operate, cannot simply be underestimated or ignored, and it is naive to assume that they would simply fall away to accommodate and support distributed leadership in schools.
\end{abstract}

Keywords: Distributed leadership, collective agency, teacher empowerment, and collaborative school culture and decision making.

\section{Introduction}

Legislative changes in education took place in South Africa since 1994. For example the South African Schools Act, no. 96, 1996 was enacted in the parliament of the Republic of South Africa and it propagates how schools should be governed. It required schools to adopt a more participatory approach in running their affairs. In essence, this provided a landscape for distributed leadership to be practiced in schools.

It is interesting to note that the bureaucratic practices in schools hasn't been scraped out, and therefore principals still have the devolved powers; and they remain the chief accounting officers in schools which means that they are ultimately responsible for anything that goes wrong in the school. The schools sampled for this study were big, carrying about 800-1100 learners, with an average of 50 educators. It is obvious that within these schools, all the problems and activities cannot be handled by the principal alone, but a team of people can lead the schools efficiently towards success. Elmore (2000: 14) argues that in a knowledge-intensive enterprise like teaching and learning, there is no way to perform these complex tasks without widely distributing the responsibility for leadership among roles in the organization.

This was the core focus of this study as it explored the distributed leadership practices in schools from a teacherbased perspective, rather than educational theorist or legislative point of view. Based on interviews with school managers (including principals) and post level one (PL1) teachers in the three sampled secondary schools falling under Johannesburg North District 10 within Gauteng province, this study examined their perceptions of distributed leadership practice. The findings revealed that distributing leadership roles provides possibilities of raising school's collective capacities, empowering staff, and collaborative school cultures and decision-making can be created. However, there are 
inherent and inevitable barriers to a distributive approach to leadership in the three secondary schools, and these are linked to the power and authority of principals as well as the policy climate within which schools operate.

\section{Literature Review / Conceptualising Distributed Leadership}

The literature review is an endeavour to get an understanding of the phenomenon under study, which is distributed leadership. Literature helps to clarify the concepts and reveal some discoveries about distributed leadership practice. Literature review on different theories of leadership was done and this helped to foreground the concept of leadership, and to eventually contextualise the distributed leadership model and also create an understanding of how it is gaining attention in relation to school leadership.

\subsection{Evaluation of leadership theories}

Theories of leadership were developed over years and can be best understood from a historical perspective. Bass (2008:4) pointed out that the concept of leadership goes back nearly as far as the emergence of civilization, which shaped its leaders as much as it was shaped by them. This implies that the study of leadership is coterminous with the rise of civilization. It is evident that leadership has been an important theme in the early years, and it continues to receive much attention in the current research works.

There are different models or theories of leadership that were developed over time and they include the trait theory, the style (behaviour) theory, and contingency theory. Seemingly there is a progression from one theory to the other. This progression can be linked to the unprecedented changes that are happening continuously. Larson (2009:51) notes that the world is changing rapidly so leaders should lead in ways that inspire all constituents within the organization to work together toward new goals.

The trait theory: This theory defines leadership as a function of an individual based on his/her personality, ability, traits and style. The key assumption of this theory is that "distinctive physical and psychological characteristics account for effective leadership (Manning and Curtis, 2002:16)". This means that leaders are born. Such traits are assumed to be "natural characteristics rather than qualities developed through response, experience or learning (Robberts and Roberts, 2007: 42-43)". It was believed people were born with these traits and only the "great people" possessed them (Northouse and Northouse, 2009: 15). Examples of such personality traits are among others, self-confidence, sociability, adaptability and co-cooperativeness. Nevertheless, the critical point remains to be the absence of universal traits of leadership. Seemingly each study on traits model come up with a particular list of traits which further extend the view that the list is endless.

The style (behaviour) theory: This theory explains the effectiveness of a leader from a behavioural or style perspective. The trait theory was silent about what leaders do; new research work attempted to explore leadership as a set of behaviours. The style or behaviour theory assumes that there is a relationship between these behaviours and the effectiveness of leaders, and that leaders are made. The style approach emphasises the behaviour of a leader, what they do and how they act towards the subordinates in various settings (Northouse \& Northouse, 2009:69).

The contingent theory: The contingent theory assumes that there is no one best approaches to organising, and that organisational structures matter when it comes to organisational performance and that the most effective method of organizing depends on the environment of the organisation. The founder of this theory is Fiedler (1973) and wanted to address the lack of attention to the context and situation of leadership practice. The Trait and Behavioural theory lacks the attention to the context and situation within which leadership is practiced or executed. This theory focused on the relationship between the context and situation of leaders' work and their actions, goals and behaviours. Effective leaders draw on the repertoire of styles and the effectiveness of a particular style is dependent upon both the leadership.

\subsection{Distributed leadership: a new perspective}

Leadership has long been viewed as the prerogative of one individual in schools rather than seen as dispersed or distributed. Contemporary schools require competences that are often greater than what one person is able to offer. This implies that leadership may no longer be exclusive to any one individual, but should be distributed among members of the organization.

The thinking in post 1994 South Africa began to change from placing the value on single leadership as the new policies promoting distributed leadership proliferated. The emphasis is now on principles of participative management where all stakeholders are involved in decision-making (Grant, Gardener, Kajee, Moodley \& Somaroo, 2010: 401) 
Gronn (2002:42) writes that distributed leadership is an alternative to the current focus on individual, solo leaders and proposes that leadership is often distributed among two, more or many members of an organization. More policy initiatives promoting distributed leadership were put in place, thus setting a stage for multiple individuals to take up leadership roles and responsibilities in schools. An example of such legislation is the South African Schools Act, no. 96 of 1996. In the context of schools, the traditional view of leadership sees leadership as synonymous to the principals because they held the power in schools, focusing on the difference they make to school (Spillane, Halverson \& Diamond, 2004: 4).

The work of Bush and Clover (2003:3) also revealed that South African schools and the wider education system display many bureaucratic features. Moonsamy (2010:1) found that much has changed, and schools are still hierarchical with the principal being the accounting officer; decisions are still made by principals as they hold formal positions of leadership, and teachers are still confined to classroom teaching. Christie, Sullivan, Duku and Gallie (2010) reported that principalship is about positional power and they may not necessarily possess leadership skills though it is thinkable that they do. So the wide formal and hierarchical structures exist with all individuals occupying positions having their job description laid down in legislation, but there can be practical ways in which people in the hierarchy can best work together.

\subsection{Defining distributed leadership}

Distributed leadership is characterized as a form of collective leadership in which teachers develop expertise by working collaboratively (Harris, 2004:14). Harris (2004:12) considers distributed leadership as leadership that can be distributed across many roles and functions in schools.

Gronn (2002) posits that a distributed view of leadership de-centres the leader and subscribes to the view that leadership resides not solely in the individual at the top, but in every person at any level who in one way or another acts as a leader. Distributed leadership is a glue of common task or goal improvement of instruction and a common frame of values for how to approach that task (Elmore, 2000: 15).

The job of those in formal leadership positions is primarily to hold the pieces of the organization together in a productive relationship. Their central task is to create a common culture that makes use of individual skills and abilities; and engage expertise wherever it exists within the organization rather than seeking this only through formal position or roles. Spillane (2002:20) maintains that the leadership task is accomplished through interaction of multiple leaders.

\section{Distributed View on Leadership}

The two exponents of this theory are Gronn $(1999,2002)$; and Spillane et al. $(2001,2004)$. This study used the views of these two exponents as the basis of the understanding and the context within which distributed leadership is applied. Hereunder follows the explanation of Gronn and Spillane's view of distributed leadership;

\subsection{Gronn's view on distributed leadership}

Gronn $(1999,2002)$ classifies distributed leadership as either numerical or concertive action, containing the properties of interdependence and coordination. He views leadership as a status ascribed to one individual, any aggregate of separate individuals, sets of small numbers of individuals acting in concert or larger plural-member organizational units (Gronn, 2002:427).

Distributed leadership as a numerical action: here Gronn (2002) suggests that all individuals in an organization may be leaders at some times. In this case distributed leadership may be seen as a sum total of all individual. Distributed leadership is numerical or multiple actions where leadership is dispersed among many or all members of the organization. There is thus a chance that all members may be leaders at some stage.

Distributed leadership as a concertive action: Gronn (2002:432) defines the attribute of concertive action as a 'conjoint agency' where the agents consisting of the members of the units act conjointly, synchronize their action by having regard to their own plans, those of their peers and the sense of unit membership.

Gronn identifies concertive action as occurring in three ways: either as spontaneous collaboration, intuitive working relations or as institutionalized practice. He sees spontaneous collaboration between individuals, occurring regularly and being anticipated in such activities as budget or planning meetings. It occurs unexpectedly because of crises in the organization. An intuitive working relation is more likely to emerge over time between colleagues who work closely together. It emerges when members of an organization are dependent on each other and develop a close personal 
relationship. He also noted two properties of distributed leadership namely interdependence and coordination. Interdependence reveals itself in two ways: by overlapping of members responsibilities and also by these responsibilities being complementary.

\subsection{Spillane's view on distributed leadership}

Spillane et al. (2001) indicate that distributed leadership is a form of collective agency incorporating the activities of many individuals in a school who work at mobilizing and guiding other teachers in the process of instrumental change. Leadership is constituted in the interaction of multiple leaders (and followers) using particular tools and artefacts around particular leadership tasks. Interdependency emerges when the enactment of the leadership task depends on the interplay between two or more actors. From a distributive perspective, followers are an essential constituting element of leadership activity. Rather than the variable outside of leadership activity that influences what leaders do or mediates the impact of what they do, followers are best understood as important part of leadership activity because leaders are dependent on the followers when they lead.

Spillane et al. (2004) argues that leadership activity is constituted, defined or constructed in the interaction of leaders with their followers and the situation in the execution of a particular leadership task. It does not reside in anyone of these elements, and each is a pre-requisite for leadership development.

Leadership occurs in situations, in actions, through the extension of influence that occurs through reciprocal interdependence required for the performance of work. In the performance of work different specializations are required.

The figure given below summarizes the views of Spillane et al. (2001) on distributed leadership. It shows that leadership works as a product of the interactions of school leaders, their followers, and their situation;

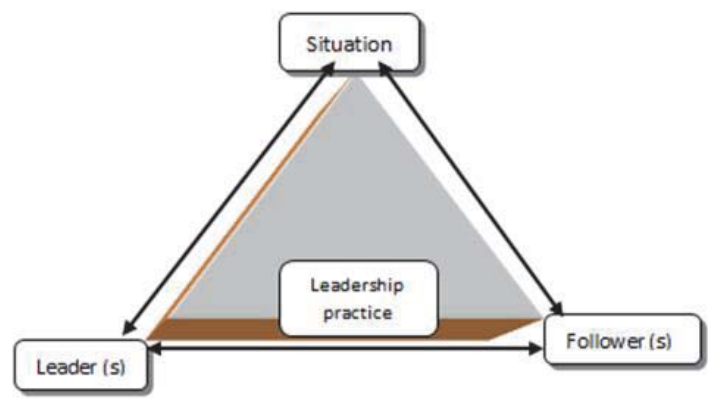

Figure 2.1: Graphic representation of Spillane's view of distributed leadership as adapted from (Spillane et al, 2001).

\section{The Research Problem}

Since 1994 official policies have focused on distributed leadership. Legislations have been developed in the parliament of South Africa to allow and encourage distributed leadership. The research shows that practices in schools do not yet incorporate distributed leadership (Grant, 2010; Grant et al, 2010; Moonsamy, 2010). So it was therefore the aim of this study to examine distributed leadership from the perspectives of teachers in relation to its practice in schools, rather than from educational theorists and legislators point of view. This researcher chose to listen to the voices of teachers who work in selected schools within Gauteng province.

\section{Research Questions}

The following questions were used to probe the perceptions of teachers during the interviews, but follow-up questions were asked during the interviews;

1. The participants' understanding of distributed leadership.

2. Can it work in schools? If yes how to facilitate it? If not what are the obstacles?

3. How wide should the boundaries be set?

4. Should the present post-level structures be changed? 


\section{Data Collection Methods}

Using a qualitative research method, data on the perception of educators of distributed leadership was collected. The main purpose of using qualitative approach was to arrive at the description of distributed leadership phenomenon from the participants' points of view during the interview.

People who operate on the same hierarchical level are more likely to speak what is in their minds openly if they are grouped accordingly to their positional levels.

There were so many challenges regarding identifying participants. Getting them to a convenient venue as a group was not possible due to their geographic locations. Other educators denied to be interviewed in the presence of others. Rather they preferred to be interviewed alone and did not prefer to go out of their schools.

In the light of the above-mentioned, this researcher decided to interview the identified participants who were ready to be interviewed. Others were interviewed in pairs and others alone. But interviews took place in each sampled school.

In an effort to triangulate the data, this researcher requested access to documents such as school organograms, minutes of staff and departmental meetings, and duty allocations in each school in the sample. The rationale was to try and reconcile what is on paper in relation to what teachers say in the interview. researchers must be quite clear about what the documents can and cannot be used for as he regards documents as "social facts" for they are produced, shared, and used in a socially organized ways. This makes it evident that researchers cannot learn from records alone as to how things happen.

\section{Data Analysis}

The data was analysed immediately after the first interview, and throughout the research process. The audio recordings during the interviews were transcribed and analysed using open coding techniques. Coding is the process of dividing data into parts by a classification system. After coding, the data was broken down, examined, compared, conceptualized and categorized in order to establish a good understanding and meaning of the opinions of the interviewed people. The data was put in different parts and groups which then assisted in creating a good understanding of all parts of the collected data.

The raw data was then segmented into concepts and categories in order to make interpretation possible. In this way the content of the transcripts was analyzed in order to identify common themes that came out of the collected data.

\section{Findings and Discussions}

The analysis of the raw data resulted into five themes which were constructed through the processes of analyzing interview transcripts. This researcher named them as follows: teamwork, teacher empowerment, and the creation of collaborative school culture. These themes emerged during the interviews. Teachers who were interviewed maintained throughout the interview that these themes are likely to be present if distributed leadership is implemented in schools.

\subsection{The possibilities provided by distributed leadership}

\subsubsection{Teamwork}

Teamwork emerged from the analysis of the data in this study as what the participants regard worthwhile. According to participant responses, teachers working in teams benefit schools in three important ways: teachers working together are better able to create shared expectations and high standards for all students; teachers working together engage in discourse that leads to creating learning experiences that are richer and of higher quality than those created by teachers working in isolation; and teachers working in teams are more effective in creating the collaborative culture that allows a school to continuously reflect on and improve its practices.

Participants in general have the same perception of the benefits of the distributed leadership in schools. They indicated that if leadership is distributed to all staff members, there is likely to be professional growth and empowerment. People will develop so much as the institution. Another benefit is that those who take up leadership roles are likely to learn a lot from such roles. This is equivalent to skill acquisition and skill development. Even if the principal is not at the school, it can run as usual because people are part of leadership; they develop a sense of belonging and ownership, their spirit is galvanized to do more and contribute positively to the development of the school.

Participants stated it throughout that if responsibilities are shared; staff members will learn to work as a team; 
"So people learn to work as a team knowing that when one leads one needs to support and be supported. So there is interdependency (P10, Interview 7: line 139-141)."

Participants also maintained that the results of teams are higher than that of individuals working alone, because when they work as a team there is interdependency and a collective effort which help to achieve good results. As they divide tasks amongst themselves in a team, they double the performance because they are able to pool their expertise. Therefore the formation of teams in schools would mean that schools are owned collectively. It emerged during the interview that distributed leadership is a form of collective agency, incorporating the activities of many individuals in a school who work at mobilizing other teachers towards bringing about change in the school.

It is evident that distributed leadership makes sharing of leadership among the staff members possible. Participants also argue that leadership is not just an attribute of those who are formally appointed as managers or heads of schools. They believe that leading never rests with just a single person but leadership is shared between members of teams. Distributed leadership is less concerned with individual capabilities, skills and talents, and is more preoccupied with creating collective responsibility for leadership action and activity. They see distributed leadership as a good model of encouraging team work and this is reflected in the following statements;

"We work as a team, team work is going to be encouraged" (P2, Interview 2: line 130-131).

"Definitely I think it; it can work because no one knows everything. So, in my view, eh, if you have different people, different expertise, then, they can work separately for the general good of the whole (P1, Interview 1: line 8-11)."

Participants indicated a need for the leadership teams to be established in schools to facilitate sharing and distribution of responsibilities. They also emphasised that teams are diverse and members have unique characteristics and are given roles based on what they can offer, that is based on their skills and strength. This is what the participant said;

"There is some form of independency and interdependency (P10, Interview 7: line 132-133)."

This statement shows that in teams, members are interdependent in their execution of tasks. The interdependency in their actions is also reciprocal. Interdependency seems important and obvious because teams are composed of people with different specialism and competencies in networks rather than hierarchies and these people are joined work together. Therefore distributed leadership calls for the involvement of others, and formation of work teams that direct their efforts towards achieving school goals. More so because the people in tend to specialize, develop certain skills and competencies and bring them to the team that are formed within the schools.

As they work as a team, the focus is shifted away from individual leaders and their personality traits, towards interactive leadership practice between leaders, followers and situation. In their interaction, team members plan, decide and act together and this is likely to make difference in school improvement. More so because the responsibility does not rest on the shoulders of one person, but on all of them in their endeavour to drive the school's performance and its student academic success. Leadership is a collective practice. If teachers take up leadership roles, they are likely to act as allies in the change process within the school, and they can be determined to achieve solidarity around school improvement goals and strategies. The following statement also indicates the importance of teams;

"Management is a part of a whole which is a team. A team that can deliver because it is coordinated, everybody has a specific role. One single individual, no matter how good they may think they are, they cannot run an institution. Institutions are run by teams because teams have got team leaders, project managers, there are people who deal specifically with certain aspects that help an institution to grow (P8, Interview 5: line 62-68)."

Participants also indicated that teams are characterized by high communicative interaction between its members. They maintained that the efficacy of team leadership relies heavily on good communication at every level and a commitment to the principle of shared decision making. In schools, effective teams are likely to have a culture of discourse at the centre, have a clearly defined purpose that guides their work towards achieving their specific and measurable goals; and are likely to be disciplined and committed in maintaining their focus; and they communicate effectively within themselves and with those outside of the teams. Participants indicated the following during the interviews;

"There must be element of communication to be effective (P3, Interview 2: line 19-20)."

So it is evident from the participants' perspectives that teams are important and can yield more benefits for the schools; and that leadership can be an important antecedent of team performance.

\subsubsection{Teacher empowerment}

Most participants agree that distribution of responsibilities provides a way of empowering the staff and nurturing of teacher leadership. By giving them opportunity to take up leadership roles, one is creating or building a broader 
leadership capacity base and the interest in taking leadership roles is stimulating among teachers. In relation to distributed leadership model as a capacity building model, participants indicated that;

"We try to give an opportunity to those people who are not in the management to take up leadership roles for the mere fact that we want to develop people to be able to can learn from those roles that they play (P10, Interview 7: line 3336)."

And they also indicated that;

"If we empower each and every one, actually one will feel owning the decision making process (P2, Interview 2: line 163-164)."

So, participants are of the view that schools should adopt distributed leadership as an alternative model and start distributing powers and responsibilities to all staff members. In this way schools will be nurturing leadership to achieve sustained improvement in schools. This further implies that for the transformational change to take place in schools, everyone should take up leadership roles. Let's have a further look at what the participants said regarding distribution of leadership roles to teachers;

"You know when you are empowered you become enthusiastic, you become galvanized in your spirit to say I want to do more (P8, Interview 5: line 27-29)."

When asked about the benefits of distributing responsibilities, participant answered;

"The benefits we can have through distributed leadership, is going to be cohesion and unity in the working relationship between the staff. Secondly it builds trust when people are recognised and work together. When only one individual is in control of everything in the school, there is more likely to be conflict and a lot of friction (P3, Interview 2: line 144-148)."

What this participant said has a directly manifestation on the capacity building model, distributed leadership, which carry within itself, social cohesion and trust. Participants also believe that distribution of powers and responsibilities is another way of building and developing capacity for continuous improvement. So they regard building leadership capacity to be the foundation of sustained school and system improvement. In relation to school-wide focus on achievement of quality, there is a need for schools to assess their staff and the school's capacity for leadership. The rationale for assessing the staff is for school to be able to identify their unique characteristics and tie them in a profitable way for the school. Participants also argued that schools should establish a set of practice that promote empowerment and growth of staff members, and one way would be through distributing leadership roles to teachers. This is what the participant in this study said;

"We need to understand that growth is driven by innovation, is driven by this thing that people have in them, this extra sensory perception of wanting to do more (P8, Interview 5: line 174-176)."

And when asked whether distributed leadership can work in school, participant answered;

"Yes, you don't have a choice. If you don't have that, it means you are removing a productivity that could otherwise been achieved, by not empowering people who are supposed to execute functions, to execute the tasks (P8, Interview 5: line 18-21)."

\subsubsection{Collaborative school culture}

Participants perceive collaboration and collegiality to be the core features of distributed leadership, and are a hallmark of any healthy school. This implies that distribution of leadership roles can help to achieve collaboration in schools whereby all members of the school community set direction, plan and solve problems collectively. This can be more relevant in today's schools as the provision of quality is becoming a complex problem. This is the voice of the participants;

"I think if people respect one another, if there is respect and trust. If you trust people that you are working with, and then it will be easy for you to do anything because whatever opinion you have, you will sit down with your people and share that and value their opinion (P6, Interview 4: line 81-85)." 
Participants also hold the view that a successful twenty-first workplace has to become flexible, agile and collaborative is improvement is desired. This may imply that if schools adopt inclusive leadership practices, they may well encourage all staff members to take up leadership roles. Participants believe that distribution of leadership roles to all teaching staff can encourage innovation in teaching, and support a school culture that is based on trust, mutual respect, sharing authority and collegiality.

Participants also maintained that distributed leadership model presents the possibility of the best solution to school problems that is generated collectively from a holistic perspective. The following statement indicates the importance of coordinated effort;

"Surely you will see results where there is coordination, you will see results (P8, Interview 5: line 303-304)."

The solution is not simply about adding more leaders, but a holistic and collaborative approach to thinking about school improvement. But participants also indicated that for distributed leadership to work in creating collaboration, it depends on the personality of the principal. This is what they said;

"It depends on personality really or how well...not educated really, but if you have open mind, and if you trust people you can allow them to do part of what you do (P5, interview 3: line 123-125)."

And that;

"It can be initiated by the principal. Because when you know your staff, you see the people who pick up (put) their hands and you ... you draw them in to get involved (P9, Interview 6: line 56-58)."

Therefore school heads who are transformational should promote an atmosphere of caring and trust among the staff, and should set a respectful tone for interaction. And all staff members should work together to develop the vision and mission of the school.

"May be at certain levels we must find a situation where we say fine, we have got the structure, but they need to be tightened up if they are not working effectively, or structured to say ok you have got management, you have got Executive Management Team (principal and deputies), you have got School Management Team (principal, deputies heads of departments and other stakeholders), you have Post Level one teachers there, and this other people who are not into curriculum issues (personnel staff). But then all of these structures must dovetail and work together in a concerted effort to help develop the school (P8, Interview 5: line 133-140)."

Participants further maintained that distribution of leadership roles can serve as a form of collective leadership practice in which teachers develop expertise by working collaboratively. The job of those in formal positions (principals) is to hold the pieces of the school together in a productive relationship, to create a common culture around the use of individual skills and abilities within the school. It is evident that where teachers share good practice and learn together, the possibility of securing better quality teaching is increased. The following participants' statements bear testimony to this;

"And you know if everybody is recognized and their potentials and abilities are taken into consideration, people are bound to work, they are bound to make the institution succeed (P6, interview 4: line 72-74)."

And also that;

"If we take part and ne...come up with a decision, we know what is happening in the field and then we can put maybe suggestions that can help everyone (P4, Interview 3: line 155-157)."

And that;

"where you are given a freedom and a leeway to think, to implement, to support, to add value, you become that much more inclined to work harder because you can see one you are being appreciate for what you do (P8, Interview 5: line 265-268)."

Participants do share in the view that distribution of tasks amongst the staff members can help create collaboration in a school and therefore bringing about interpersonal relationships which is filled with respect, trust and optimism. 
Participants in this study highlighted the importance of an invitational approach by those in formal positions of authority. They emphasized that if they do not invite others the opposite may be the case. This is what they said;

\begin{abstract}
"The management should invite everybody because every person can contribute something positive or some way of thinking which the management if working alone could realise or consider." So it must be open (P9, Interview 6: line 7578)."
\end{abstract}

Another participant's perceptions is that;

\begin{abstract}
"The person who is the manager, who controls other teachers, his way of leadership, will determine how leadership is shared. If he can say ladies and gentleman this is our school, who thinks can be responsible for these tasks? If he calls for people to volunteer or maybe give responsibilities to all the teachers on certain areas, then it can work. But now it depends on whether this particular leader (principal) in the school is willing to share his power and authority or not. (P1, Interview 1: line 19-27).
\end{abstract}

\title{
8.2 The envisaged role of school principals
}

It is evident that in a knowledge-intensive enterprise like teaching and learning, the principal can find it difficult to perform the complex task of managing and leading the school without widely distributing the responsibility for leadership roles among teachers in the school. Participants in this study have suggested the following to be the new roles of principals in the twenty-first century schooling system if indeed distributed leadership model has to be implemented in schools;

\subsection{Decentralisation of power and authority}

This involves breaking down hierarchical barriers and reach out to staff members ad enable them to influence decisions that affect their work. Participants regard decentralization of power and authority as equivalent to distribution of leadership roles and the assumption is that if the principal has too much important work to do, he or she has to give some of the work and decision away to other staff members. In this way, those in formal positions decentralize responsibilities; decentralize authority and powers to all levels of practice. Participants see this as a way of fostering leadership at all levels and of ensuring that leadership activities are widely shared within the school. And they believe that sharing responsibilities can help reduce the stress of being a school principal. These are the participants' statements on decentralization of responsibilities;

"I think distributed leadership is the decentralization of leadership, rather than for leadership to be centred on one person in one office like the principal's office. It must be decentralized to all the members of the staff (P3, Interview 2: line 12-15)."

And the participants further maintained that decentralizing leadership has certain benefits because:

"It creates opportunity for people to do managerial activity apart from just being the manager of the class, and this then empowers them (P9, Interview 6: line 44-45)."

The participant's view is that staff members should be actively and collectively involved and participate in the school activities and processes; and also feel that their contributions are valued. Participants hold that all staff members can play a key role in bringing about school improvement. But they indicated that power is still centralized at the top;

"It's unfortunate that you still find power in schools, centralized at the top, but efficiency and productivity is still expected from people (staff members), people who do not understand what is it that is being asked of them"(P8, Interview 5: line 12-16)."

However participants suggest that;

"Institutions must have this overarching structure that allows for individual input without criticism or without disdain, simply because somebody is high above you in terms of the power dynamics, the power structure, and it doesn't mean they know better than you door anybody else in the school (P8, Interview 5: line 187-191)."

And this is desirable because; 
"Sometimes you can undermine post level one teachers but they can come up with a good opinion that will help the school to achieve better results at the end of the year. (P7, Interview 4: line 64-67)."

The emphasis here is that school principals should de-centre leadership and to subscribe to the view that leadership resides not solely in the individual at the pinnacle, but in every person at any level who in a way acts as a leader. They should give others opportunities to take up leadership roles.

\subsection{Emerging challenges in the sampled secondary schools}

The participants in this research reflected on certain challenges that are faced in the three sampled secondary schools. Factors identified as challenges in practising distributed leadership in schools include fear by school managers to be exposed of their weakness, and the applied policies of the department of education do place certain barriers to the distribution of leadership roles. The discussions of these factors follow hereunder;

\subsubsection{Fear by principals to expose their own weaknesses}

Senior managers including principals, who participated in this study, expressed and acknowledged that they at times do not share leadership roles with their staff because they fear that staff members may perform such roles better and do things differently. It is likely to make principals not feel comfortable when they occupy the highest senior positions in the school and yet are outclassed by post level one teachers in executing management and leadership tasks. The following statement comes from one of the principals who participated in this study;

"Generally I can agree that there is fear to be exposed by others by their strength with regard to leadership. It is sometimes there with leaders, and the fear can influence your decision with regard to distribution of leadership".

Problems or barriers of this nature seem to be inherent and demonstrate that the status quo remains in schools. Distributed leadership requires those in formal leadership positions to relinquish power to others. Principals and/or senior managers seem to find this problematic because it challenges their authority and ego; and this potentially places the head or the principal in a vulnerable position because of the lack or loose direct control over certain activities that are run by teachers within the school if distributed leadership model is implemented.

And what the participants perceive is that;

"Most of the time decisions are made by school managers behind closed doors without involving other teachers. It's like they are closing doors and opportunity for us to play roles in running the school's affairs, (P, Interview 3: line 149-151)".

This clearly shows that some principals in the sampled schools are not educationally inviting to those they work with. They still hold on to their positional powers and seemingly do not want to give away authority to staff members. In that way may not be easy to summon other stakeholders' potential and draw them to be part of the process of running the schools affairs. When those formally appointed as leaders in schools attempt to get the rest of the staff to do what is wanted without involving them, it becomes just a lost cause in essence. Professional invitation has to do with inviting staff members to be part of the process..

\subsubsection{Policies that govern schools operation}

Clearly, schools are traditional hierarchies as mandated by departmental policy, and have the demarcations of positions with different pay-scales. The Public Administrative Measures explains the roles and responsibilities of each position within the hierarchy, and each post level earns a different pay-scale. This implies that each senior post within the hierarchy carries additional financial increments and status. Seemingly there is no sign for this to change immediately, which therefore suggests that this will remain an inherent status quo for sometimes. In this environment, a more fluid and distributed approach to leadership seem unlikely to happen.

In their work, Fitzgerald and Gunter (2007:6) questioned the possibility for distributed leadership to occur in a policy climate that affords authority and responsibility for leadership and management to those labelled according to an established hierarchy. Also as Harris (2009:13) argues, the existing hierarchical schooling structure will always mediate against distributed leadership practice and this would make this type of informal influence and agency impossible possible to practice 


\section{Conclusion}

This study revealed that if school principals can relinquish some of their powers and distributes them to teachers, they can be empowered in leadership roles outside the classroom and collective agency may develop. As a result schools may achieve success through teamwork, collaborative school culture and decision making. However the bureaucratic practice in schools cannot simply be stopped because that logic of practice serves its own purpose. It would be naïve to assume that the structural barrier, coupled with the character of principals and the status inherent in such positions, would simply fall away to accommodate and support distributed leadership. This difficulty cannot simply be underestimated or ignored. The question is how can these challenges be addressed so that leadership in schools become a collective effort and not rest on one individual?

\section{Acknowledgements}

I thank all the teachers and principals who participated in this research project and the department of education (GDE) for giving me the opportunity to conduct a research on this topic which has started to receive attention, and not forgetting Professor Pierrie du Plessis for his guidance and input into of this study.

\section{References}

Bass, B.M., \& Bass, R. (2008). The Bass Handbook of leadership: Theory, Research and Managerial Applications. 4the Edition. New York: Free Press.

Bush, T., Clover 2003. School leadership: concepts and evidence: summary report. Britain: NCSL

Christie, P., Sullivan, P., Duku, N., \& Gallie, M. 2010. Researching the need: school

leadership and quality of education in South Africa. Report prepared for Bridge,

South Africa and ARK, UK.

Elmore, R. 2000. Building a new structure for school leadership. Washington: The Abert Shanker Institute

Fitzgerald, T., \& Gunter, M. 2007. Teacher leadership: a new myth for our time. Chicago: AERA

Grant, C. 2010. Distributed teacher leadership: troubling the terrain. Unpublished PhD thesis. Pietermaritzburg: Univesity of KwaZuluNatal.

Grant, C., Gardner, K., Kajee, F., Moodley, R., \& Somaroo, S. 2010. Teacher leadership: a survey analysis of KwaZulu-Natal teachers' perceptions. South African Journal of Education, 30:401-419.

Gronn, P. 1999. Substituting for leadership: the neglect role of leadership couple. Leardership Quarterly, 10(1): 41-62.

Gronn, P. 2002. Distributed leadership as a unit of analysis. The Leadership Quarterly, 13(4): 423-451.

Harris, 2004. Distributed leadership for school improvement: leading or misleading. Educational Management Administration and Leadership, 32 (1): 11-24.

Harris, A. 2009. Distributed Leadership: different perspectives, studies in leadership. London: Springer.

Larson, J. (2009). Transformational leadership. Leading schools in a time of Global Cultural shifts. Independent school, 68 (3): 51-58.

Manning, G., \& Curtis, K. 2002. The art of leadership. New York: McGraw Hill.

Moonsamy, J. 2010. Teacher leadership made visible: a case study of three teacher leaders in a semi-urban secondary school in KwaZulu-Natal. Unpublished M.ed dissertation. Pietermaritzburg: University of KwaZulu Natal.

Northouse, P.G., \& Northouse, P.G. 2009. Leadership: Theory and Practice. 5th Edition. Thousand Oaks: Sage Publishing, Inc

Republic of South Africa 1996. South African Schools Act (Act No. 84 of 1996). Government Gazzette No. 17579, 15 November.

Robberts, D.C., \& Roberts, D.C. 2007. Deeper learning in leadership: helping college students find the potential. San Franscisco: Jossey-Bass.

Spillane, J.P., Halverson, R., \& Diamond, J. 2001. 'Towards a Theory of Leadership Practice: A Distributed Perspective'. Institute for Policy Research Working Article.

Spillane, J.P., Halverson, R., \& Diamond, J.B. 2004. Towards a theory of leadership practice: a distributed perspective. Journal of curriculum studies, 36(1): 3-34. 